\title{
Family eczema-history in 2-year olds with eczema; a prospective, population-based study. The PACT-study, Norway
}

Marit Saunes ${ }^{1,2^{*}}$, Torbjørn Øien ${ }^{1}$, Ola Storrø ${ }^{1}$ and Roar Johnsen ${ }^{1}$

\begin{abstract}
Background: A maternal line of inheritance regarding eczema has been described in several studies, whereas others find associations to both a maternal as well as a paternal line of inheritance. When studying family history of eczema symptoms, cohort studies including siblings are rare. Time point for assessing family eczema-history could be of importance when studying the associations between family eczema-history and children with eczema, as parents with unaffected children may not recall mild symptoms in other siblings or their own disease history. We therefore aimed to study the associations between reported eczema in mother, father and siblings and reported eczema in index child where information on family history was collected at two different ages of index child.

Methods: Parents/children participating in The Prevention of Allergy among Children in Trondheim (PACT) study were given questionnaires on reported eczema symptoms in mother, father and siblings at 6 weeks and 1 year. When index child was 2 years of age, a detailed questionnaire on different health issues with emphasize on different allergy related disorders were filled in.

Results: Both maternal and paternal reports on eczema were significantly associated with eczema in index child. Reporting family eczema-history at 1 year $(N=3087)$, "eczema sibling only" [adjusted odds ratio $(a O R)=3.13$ (2.274.33)] as well as all other family-groups containing siblings with eczema were strongly associated with eczema 2 years. When family eczema-history was reported at 6 weeks $(N=2657)$, reporting of "eczema sibling only" was not associated to reported eczema at 2 years in index child [aOR $=1.31(0.77-2.23)]$.

Conclusions: Having sibling(s) with eczema strengthened the associations between maternal and paternal reports on eczema with eczema in index child only when exposure was reported at 1 year. These findings indicate that results from questionnaires-based studies of family eczema-history depend on whether or not index child has yet developed eczema.
\end{abstract}

Trial registration: ISRCTN: ISRCTN28090297

\section{Background}

Atopic eczema is a complex disease caused by a mainly unknown interaction between genetic and environmental factors [1]. The genetic component of the disease has been demonstrated in twin studies [2], and several studies have emphasized the association of atopy in the mother with the development of atopic eczema in the

\footnotetext{
* Correspondence: marit.saunes@ntnu.no

'Department of Public Health and General Practice, Norwegian University of Science and Technology, Trondheim, Norway

Full list of author information is available at the end of the article
}

child whereas the evidence for association to an atopic father has been somewhat weaker [3-6]. In the last years, however, other studies have concluded that the association with both paternal as well as maternal atopy is important in the development of allergic disease in the offspring [7-10] Several candidate genes linked to the development of eczema have been identified [11], but so far only mutations in the gene encoding filaggrin (FLG) have been widely replicated [12].

When family eczema-history is studied, several investigators have studied the protective effect of having a high

\section{Biomed Central}


number of siblings on the development of allergic diseases $[13,14]$. However, few prospective studies from the general population have addressed the association between allergy related disorders in older siblings and the child under study $[4,15]$.

When studying diseases in the general population, self-reported questionnaires are often used. One of the flaws with such information could be recall bias concerning how well adults remember both their own childhood diseases as well as diseases in children with mild symptoms [16-18].

The aim of this prospective study was therefore to investigate the associations between reported eczema in mother, father and siblings and reported eczema in index child at 2 years of age where family eczema-history as well as exposure was collected at two different ages of the index child.

\section{Methods}

The Prevention of Allergy among Children in Trondheim (PACT) study is a large population- based prospective study on allergy related disorders conducted in Trondheim, central Norway. Trondheim has approximately 165000 inhabitants and 2100 deliveries pr year.

From September 2000 all pregnant women as well as children 6 weeks, 1 year, and 2 years of age visiting their general practitioner or community based midwife were consecutively invited to attend the study. Women/ parents were eligible to participate if they were able to complete a questionnaire in Norwegian. Recruitment of 6 weeks old, 1 year and 2 years old children closed June $30^{\text {th }}$ 2006. The PACT-study is described in further detail elsewhere [19].

\section{-Study design}

Family eczema-history and exposure variables was assessed from questionnaires when the child was 6 weeks old (Q2) and 1 year old (Q3) [19]. When the child was approximately 2 years of age, the parents answered a questionnaire on the child's health (Q5). The questionnaires Q2 and Q3 included questions on different allergic diseases in parents/siblings (including family eczema-history) as well as on indoor climate, infections, medication, vaccines, day-care, exposure to nicotine, pets, breastfeeding and diet. Q5 included questions on different health issues in index child with emphasize on allergy related disorders. The latter questions were adopted from the International Study of Asthma and Allergies in Childhood (ISAAC) protocol and modified to fit the actual age group [20].

By March 2009 some 2657 parents (54.6\%) had completed Q2 as well as the child's health-questionnaire at the age of 2 years (Q5), and these are included in the 6 weeks cohort. The 1 year cohort comprises 3087 parents (60\%) who had completed Q3 together with Q5 (table 1).

These two cohorts ( 6 weeks, $\mathrm{N}=2657$ and 1 year, $\mathrm{N}$ $=3087$ ) were used to prospectively study reported family eczema-history and association to eczema in index child reported at 2 year.

\section{-Study variables}

-The outcome variable studied was ever eczema reported at the age of 2 years (Q5). The index child was defined as having eczema if both questions "Has your child ever had eczema?" and "Has your child ever had an itchy rash which was coming and going for at least 6 months?" were answered positively [21].

Family eczema-history and exposure variables were assessed in Q2 and Q3.

-Family eczema- history

Eczema in mother, father or sibling was defined as "yes" if any one of the questions "have you, the child's father or any of your joint children ever had eczema" or "have you, the child's father or any of your joint children had eczema or used medication against eczema during the last 12 months" were ticked "yes" for mother, father or sibling.

The reporting of family eczema history was then categorized into the seven different family eczema groups possible; "mother only", "father only", "sibling only", "mother and father", "mother and sibling", "father and sibling", "mother, father and sibling".

\section{-Exposure variables}

The term "breastfeeding now" was used regardless of whether or not solid food or formulas was given to the child in addition to breast milk.

"Current smoking mother" was regarded as "yes" when the question "do you smoke now?" was answered positively.

Maternal and paternal level of education was not accounted for in the original questionnaire. Thus, homeowner status from the questionnaire was used as a proxy for socioeconomic status.

"Dampness" was defined "yes" when the sum of 8 different questions concerning damp/mould at home was 3 or more.

\section{-Ethics}

All parents signed a written consent form to participate in the PACT study. The study was approved by the Regional Committee for Medical Research Ethics and the Norwegian data Inspectorate Board (Ref 120-2000) (Ref 2003/953-3 KBE/-).

\section{-Statistics}

Univariate associations between eczema in index child and different family eczema-groups as well as the 
Table 1 Characteristics of the two study populations with exposure reported at 6 weeks and 1 year

\begin{tabular}{|c|c|c|c|c|c|c|c|}
\hline \multirow[b]{2}{*}{ Reported exposure ${ }^{a}$} & & \multicolumn{3}{|c|}{ Exposure reported at 6 weeks, $\mathrm{N}=2657$} & \multicolumn{3}{|c|}{ Exposure reported at 1 year, $\mathrm{N}=3087$} \\
\hline & & $\underline{\mathrm{n}}$ & $\underline{\%}$ & $(95 \% \mathrm{Cl})$ & $\underline{\mathrm{n}}$ & $\%$ & $95 \% \mathrm{Cl}$ \\
\hline Gender & Male & 1333 & 50.2 & $(48.3-52.1)$ & 1529 & 49.5 & $(47.8-51.3)$ \\
\hline Homeowner & Yes & 2242 & 84.4 & $(82.9-85.7)$ & 2680 & 86.8 & $(85.6-88.0)$ \\
\hline Cat & Yes & 239 & 9.0 & $(7.9-10.1)$ & 266 & 8.6 & $(7.7-9.7)$ \\
\hline Dog & Yes & 247 & 9.3 & $(8.2-10.5)$ & 249 & 8.1 & $(7.1-9.1)$ \\
\hline Bird & Yes & 63 & 2.4 & $(1.8-3.0)$ & 70 & 2.3 & $(1.8-2.9)$ \\
\hline Dampness & Yes & 105 & 4.0 & $(3.2-4.8)$ & 117 & 3.8 & $(3.1-4.5)$ \\
\hline Maternal current smoking & Yes & 189 & 7.1 & $(6.2-8.2)$ & 453 & 14.7 & $(13.4-16.0)$ \\
\hline Paternal current smoking & Yes & 399 & 15.0 & $(13.7-16.4)$ & 499 & 16.2 & $(14.9-17.5)$ \\
\hline Premature birth, $<37$ weeks & Yes & 75 & 2.8 & $(2.2-3.5)$ & 75 & 2.4 & $(1.9-3.0)$ \\
\hline \multirow[t]{3}{*}{ Birth-weight } & $<2500 \mathrm{gr}$ & 74 & 2.8 & $(2.2-3.5)$ & 105 & 3.4 & $(2.8-4.1)$ \\
\hline & $2500-3999 \mathrm{gr}$ & 1937 & 72.9 & $(71.2-74.6)$ & 2196 & 71.1 & $(69.5-72.7)$ \\
\hline & $\geq 4000 \mathrm{gr}$ & 623 & 23.4 & $(21.8-25.1)$ & 691 & 22.4 & $(20.9-23.9)$ \\
\hline Breastfeeding now & Yes & 2481 & 93.4 & $(92.4-94.3)$ & 1114 & 36.1 & $(34.4-37.8)$ \\
\hline \multirow[t]{3}{*}{ Number of siblings } & 0 & 1172 & 44.1 & $(42.2-46.0)$ & 1343 & 43.5 & $(41.7-45.3)$ \\
\hline & 1 & 920 & 34.6 & $(32.8-36.5)$ & 1033 & 33.5 & $(31.8-35.2)$ \\
\hline & 2 or more & 533 & 20.1 & $(18.6-21.6)$ & 711 & 23.0 & $(21.6-24.6)$ \\
\hline Any kind of infection, child & Yes & 903 & 34.0 & $(32.2-35.8)$ & 2983 & 96.6 & $(95.9-97.2)$ \\
\hline \multirow[t]{2}{*}{ Antibiotics ever, child } & Yes & 58 & 2.2 & $(1.7-2.8)$ & 706 & 22.9 & $(21.4-24.4)$ \\
\hline & mean & range & SD & & mean & range & SD \\
\hline Maternal age & 30.1 & $17-48$ & 4.49 & & 29.98 & $17-48$ & 4.46 \\
\hline
\end{tabular}

${ }^{\mathrm{a}}$ Number of missing varies

different exposure variables were analysed using simple logistic regression.

Associations adjusted for potential confounders were obtained by logistic regression models. Maternal age was used as a linear variable in the regression analysis. All other explanatory variables were either dichotomized or categorized. Dummy variables were made when the independent variables contained more than two categories. Family eczema-groups were also categorized, and those with no family history of eczema (mother, father or sibling) were set as reference group.

The logistic regression models were adjusted for confounding factors identified by a priori knowledge to the problem being studied. In the final multivariable regression analysis, adjustments were made for gender, homeowner, current smoking mother, breastfeeding, keeping a dog and age of mother at the time of birth.

A separate model was made for older siblings with and without eczema. In addition to adjustment for the $a$ priori defined confounding factors, adjustment was made for eczema mother and eczema father. Interaction between eczema mother and eczema father was tested.

In the multivariable analysis the number of missing varied for each variable under study, but never exceeded $9 \%$.

Unadjusted and adjusted associations are presented as odds ratios (OR, aOR). 95\% confidence intervals (CI) were estimated for binominal distributed data.
Statistical Package for Social Science version 15.0 (SPSS inc., Chicago; IL, USA.) and STATA version 11.2 for Windows (STATA Corporation, College Station, TX, USA) were used for the analyses.

\section{Results}

Some $13.7 \%$ and $14.2 \%$ of the girls, and $15.9 \%$ and $16.1 \%$ of the boys reported eczema at 2 years of age in the 6week cohort $(\mathrm{N}=2657)$ and in the 1 -year cohort $(\mathrm{N}=$ 3087), respectively.

When exposure was reported at 6 weeks, only some $6 \%$ of the index children with eczema had had their first symptoms of eczema, whereas the corresponding number was about $80 \%$ among those who reported exposure at 1 year.

Some $77 \%$ of children in the 6 -week cohort also attended the 1-year cohort. Between 6 weeks and 1 year, some $9.6 \%$ of these parents changed their answer from "no" to "yes" regarding whether or not the index child had a sibling with eczema or not. Among those with eczema in index child reported at 2 years, some $28.5 \%$ changed their answer from "no" to "yes" from 6 weeks to 1 year, as opposed to some $6.4 \%$ among those without eczema in index child 2 years (data not shown).

In univariate analyses, keeping a dog was the only statistically significant environmental factor associated with reported eczema at 2 years of age in both cohorts. 
When reporting family history at 6 weeks, the association between eczema in index child at 2 years and different eczema- groups containing only one or both of the parents, both "eczema mother only" and eczema father only" were statistically significant in the univariate analyses [(OR, 1.61; 95\% CI 1.18-2.21), (OR, 1.69; 95\% CI 1.16-2.46)] (table 2). When adding reporting of eczema in a sibling to eczema in one or both of the parents, we found "eczema mother and sibling, not father" and "eczema mother, father and sibling" to be significantly associated with eczema in the index child at 2 years [(OR, 3.41; 95\% CI 1.91-6.10) and (OR, 3.15; 95\% CI 1.42-7.02)].

Corresponding univariate analyses of different family history eczema-groups reported at 1-year showed no differences in associations with eczema in index child at 2 years for any of the groups containing one or both of the parents without a sibling compared to 6 weeks. For all groups including eczema in siblings there were a consistent and highly significantly association with eczema at 2 year in the index child (table 2).

In the adjusted model, we found a significant association between "eczema mother only" and "eczema father only" reported at 6 weeks and eczema in the index child at 2 years [(aOR, 1.57; 95\% CI 1.13-2.18), (aOR, 1.73; 95\% CI 1.18-2.55)] (table 3). No association was found with "eczema sibling only" (aOR, 1.31; 95\% CI 0.77-2.23).

When adapting the same model on reported eczema in mother, father and sibling at 1 year, we found a significant association with eczema at 2 years in all groups but "eczema mother and father" (Table 3). As opposed to the family eczema-history reported at 6 weeks, a significant association was observed for "eczema sibling only" (aOR, 3.13; 95\% CI 2.27-4.33). Adding eczema in
Table 3 Adjusted association between different family eczema-groups and eczema 2 years ${ }^{\text {a,b }}$

\begin{tabular}{|c|c|c|c|c|}
\hline & \multicolumn{2}{|c|}{$\begin{array}{c}\text { Reported at } 6 \\
\text { weeks }\end{array}$} & \multicolumn{2}{|c|}{$\begin{array}{c}\text { Reported at } 1 \\
\text { year }\end{array}$} \\
\hline & $\mathrm{aOR}$ & $(95 \% \mathrm{Cl})$ & $\mathrm{aOR}$ & $(95 \% \mathrm{Cl})$ \\
\hline Eczema mother only & 1.57 & $\begin{array}{l}(1.14- \\
2.18)\end{array}$ & 1.62 & $(1.17-2.24)$ \\
\hline Eczema father only & 1.73 & $\begin{array}{l}(1.18- \\
2.55)\end{array}$ & 1.98 & $(1.35-2.90)$ \\
\hline $\begin{array}{l}\text { Eczema mother and father, not } \\
\text { sibling }\end{array}$ & 1.83 & $\begin{array}{l}(0.97- \\
3.42)\end{array}$ & 1.73 & $(0.91-3.28)$ \\
\hline Eczema sibling only & 1.31 & $\begin{array}{l}(0.77- \\
2.23)\end{array}$ & 3.13 & $(2.27-4.33)$ \\
\hline $\begin{array}{l}\text { Eczema mother and sibling, not } \\
\text { father }\end{array}$ & 2.59 & $\begin{array}{l}(1.34- \\
5.00)\end{array}$ & 4.48 & $(2.96-6.78)$ \\
\hline $\begin{array}{l}\text { Eczema father and sibling, not } \\
\text { mother }\end{array}$ & 2.14 & $\begin{array}{l}(0.99- \\
4.63)\end{array}$ & 5.43 & $(3.27-9.02)$ \\
\hline Eczema mother, father and sibling & 3.78 & $\begin{array}{c}(1.66- \\
8.63)\end{array}$ & 6.25 & $\begin{array}{l}(3.09- \\
12.65)\end{array}$ \\
\hline
\end{tabular}

a ) No family eczema is the reference point for all other family eczema-groups $\left.{ }^{b}\right)$ Model adjusted for gender, homeowner, current smoking mother, breastfeeding, keeping a dog and age of mother at time of birth.

sibling to either of the eczema parent groups significantly strengthened the associations in the 1 year cohort; "eczema mother and sibling, not father" (aOR, 4.48; 95\% CI 2.96-6.78), "eczema father and sibling, not mother" (aOR, 5.43; 95\% CI 3.27-9.02).

In the model testing association between siblings with and without eczema and association to eczema in index child 2 years, we found a significant association for siblings with eczema in the 1 year cohort only (aOR, 2.18; 95\% CI 1.63-2.92). No interaction between eczema mother and father was found in either of the cohorts $(p$ for interaction $=0.48$ at 6 weeks, $p$ for interaction $=$ 0.10 at 1 year) (data not shown).

Table 2 Univariate association between different family eczema-groups and eczema 2 years

\begin{tabular}{|c|c|c|c|c|c|}
\hline & $\begin{array}{l}\text { Proportion of children with } \\
\text { eczema } 2 \text { years }\end{array}$ & $\begin{array}{l}\text { OR }(95 \% \\
\text { Cl) }\end{array}$ & & $\begin{array}{l}\text { Proportion of children with } \\
\text { eczema } 2 \text { years }\end{array}$ & $\begin{array}{l}\text { OR }(95 \% \\
\text { CI) }\end{array}$ \\
\hline Reported 6 weeks & & & Reported at 1 year & & \\
\hline No family eczema ${ }^{a}$ & $12.5 \%(217 / 1738)$ & 1.0 & No family eczema ${ }^{a}$ & $10.7 \%(201 / 1885)$ & 1.0 \\
\hline Eczema mother only & $18.7 \%(61 / 326)$ & $\begin{array}{c}1.61 \\
(1.18-2.21)\end{array}$ & Eczema mother only & $16.7 \%(59 / 354)$ & $\begin{array}{l}1.68(1.22- \\
2.30)\end{array}$ \\
\hline Eczema father only & $19.4 \%(39 / 201)$ & $\begin{array}{c}1.69 \\
(1.16-2.46)\end{array}$ & Eczema father only & $18.1 \%(39 / 215)$ & $\begin{array}{l}1.86(1.27- \\
2.71)\end{array}$ \\
\hline $\begin{array}{l}\text { Eczema mother and father, } \\
\text { not sibling(s) }\end{array}$ & $19.7 \%(13 / 66)$ & $\begin{array}{c}1.72 \\
(0.92-3.21)\end{array}$ & $\begin{array}{l}\text { Eczema mother and father, } \\
\text { not sibling(s) }\end{array}$ & $16.0 \%(12 / 75)$ & $\begin{array}{l}1.60(0.85- \\
3.01)\end{array}$ \\
\hline Eczema sibling(s) only & $16.9 \%(22 / 130)$ & $\begin{array}{c}1.43 \\
(0.88-2.31)\end{array}$ & Eczema sibling(s) only & $25.5 \%(67 / 263)$ & $\begin{array}{l}2.86(2.09- \\
3.92)\end{array}$ \\
\hline $\begin{array}{l}\text { Eczema mother and sibling } \\
(\mathrm{s}) \text {, not father }\end{array}$ & $24.1 \%(19 / 79)$ & $\begin{array}{c}3.41 \\
(1.91-6.10)\end{array}$ & $\begin{array}{l}\text { Eczema mother and sibling } \\
\text { (s), not father }\end{array}$ & $33.9 \%(42 / 124)$ & $\begin{array}{l}4.29(2.88- \\
6.40)\end{array}$ \\
\hline $\begin{array}{l}\text { Eczema father and sibling } \\
\text { (s), not mother }\end{array}$ & $23.1 \%(9 / 39)$ & $\begin{array}{c}2.10 \\
(0.99-4.49)\end{array}$ & $\begin{array}{l}\text { Eczema father and sibling } \\
(\mathrm{s}) \text {, not mother }\end{array}$ & $37.5 \%(27 / 72)$ & $\begin{array}{l}5.03(3.05- \\
8.28)\end{array}$ \\
\hline $\begin{array}{l}\text { Eczema mother, father and } \\
\text { sibling(s) }\end{array}$ & $31.0 \%(9 / 29)$ & $\begin{array}{c}3.15 \\
(1.42-7.02)\end{array}$ & $\begin{array}{l}\text { Eczema mother, father and } \\
\text { sibling(s) }\end{array}$ & $40.0 \%(14 / 35)$ & $\begin{array}{l}5.59(2.80- \\
11.16)\end{array}$ \\
\hline
\end{tabular}

\footnotetext{
${ }^{a}$ No family eczema is the reference point for all other family eczema-groups
} 


\section{Discussion}

In this large population based study with reports of family eczema-history at two different points of time, we found that having either parent with eczema was significantly associated with reported eczema at the age of 2 years. The associations were consistent when reported at 6-weeks as well as 1 year. Having one or several siblings with eczema, with or without either of the parents with eczema reported at 1 year, was also strongly associated with reported eczema at 2 years and significantly stronger for siblings only.

We have data on exposure reported at 6 weeks and 1 year. Although the reporting of exposure was at two different points of time, the two cohorts are comparable. Some 77\% of those who answered Q2 (6 weeks) also answered Q3 (1 year) as well as Q5 (2 years). The two cohorts are generated from the same geographic area (the city of Trondheim), during the same time-period, and by the same midwifes and GPs.

Although eczema is a relatively prevalent disease among children in the western world, most children have mild degree of disease, making the diagnosis and differentiating between different phenotypes of the disease as well as mild cases challenging [21-23]. We found the prevalence of reported eczema 2 years to about $15 \%$ both among those who reported the family eczema history at 6 -week and those who reported at 1 year, indicating a high reliability of the questions. Any misclassification of eczema cases might therefore be non-differential, and if so may have diluted the associations.

Several studies describe a maternal line of inheritance concerning eczema $[5,6,22]$. This maternal line of inheritance has led investigators to hypothesize that environmental influences operating in utero or in early infancy may be essential in determining disease expression [24]. In this study eczema in the index child was significantly associated with eczema in mothers as well as fathers. This finding is in accordance with several others $[8,9,25]$ and not supportive to the hypothesis of paternal genomic imprinting. However, parental recall bias should be taken into consideration also here. Any one parent who followed the child was asked to participate in the PACT-study. One limitation in this study is the fact that we don't know which parent filled in the questionnaire. Since many of the women were included during pregnancy and during their child's first year of living, we assume that mothers most likely have accepted to participate in the study when visiting her GP or midwife. It is therefore most likely that mothers have filled in the questionnaires. In both cohorts more boys than girls reported eczema at age 2 years. Despite this, more mothers than fathers reported to have ever eczema. When studying recall bias in parental questioning, a
German group found that mothers tended to report more atopic diseases in a second questionnaire than in the first, whilst fathers were influenced by their child's development of atopic disease [16]. In families without childhood eczema the sensitivity for mothers reporting paternal eczema was lower than in families with at least one child with eczema. The specificity was about the same [26]. Although effect size is small in a population setting, filaggrin haploinsufficiency is a highly penetrant trait, and associated with increased eczema severity [27]. It is therefore likely that severe eczema in any one of the parents represent a greater risk of eczema in the offspring. It seems also likely, that mothers more often would report a positive paternal history of eczema if the disease was severe or persisted into adulthood. The latter is supported by a Swedish study, who found that recall of childhood eczema history among adults was influenced by several factors such as high prevalence of eczema after the age of 15 , more visits to the physician after the age of 15, more hand eczema and more sickleave due to eczema [17]. Since mothers most likely have filled in our questionnaires, an overestimation of the association between paternal eczema and eczema in index child is possible. This might be due either to more severe eczema in fathers or increased awareness due to development of eczema in one of the children. Both could explain the lack of a maternal line of inheritance in this study.

When family history of eczema is studied, allergy related disorders in siblings are seldom accounted for in the risk analysis. We found that, although having any one parent with eczema was associated with eczema in index child at 2 years, having one or several siblings with eczema together with mother and/or father with eczema was strongly associated with eczema in index child 2 years when reports were collected at 1 year. This association was also seen when eczema was reported only in sibling(s). There are different interpretations of these findings. One possible explanation could be that this is a reflection of a parental genetic disposition with incomplete penetrance [4]. Mutations in the gene encoding filaggrin (FLG) have been identified as a strong predisposing factors for eczema [28] and especially severe phenotypes of the disease [29], but other candidate genes are also under investigation [11]. Different environmental factors can alter the expression of different genes, as have been showed with the exposure to cat within the first year of life in those who carry mutations of FLG [30]. Other environmental factors such as early colonisation from maternal microbial flora as well as shared environment among siblings with the same genetic predisposition may act in a similar way and explain the "eczema-sibling-effect" in this study. 
The "eczema-sibling-effect" was not significant when reported at 6 weeks. Awareness of disease in first child with mild disease might be absent until same kinds of symptoms as e.g. dry skin is observed in second child. Also, in mild cases of eczema a significant proportion of the children are disease free by the age of 3 years [31]. In this study, some $28.5 \%$ of parents with eczema in index child at 2 years changed their answer from "no" when reported at 6 weeks to "yes" when reported at 1 year regarding the question on whether or not siblings had eczema, as opposed to $6.4 \%$ among those without eczema in index child. These findings could be interpreted as an increase in awareness since some $80 \%$ of index children had developed symptoms on eczema at age 1 year. Another interpretation is that some of the older siblings have not yet been diagnosed with eczema. This is however less likely, since a majority of children with eczema starts with their disease during their first year of life [31].

In a German study of children 9-11 years old having two first degree relatives with the same atopic disease was highly associated with eczema [4]. Diepgen \& Blettner found a stronger correlation between siblings than between siblings and parents for all atopic diseases, also atopic dermatitis [5]. Eczema in an older sibling was also found to be an independent risk factor for eczema among 4-years old in Sweden [9].

When only some $60 \%$ of those finishing the questionnaires on exposure were answering the questionnaires on health, one could argue that the data are prone to self-selection. In both cohorts the lost-to-follow-up group contained more current smoking mothers and fewer homeowners, indicating a lower socio-economic status (data not shown). However, other exposure data, including reported family eczema-history did not differ among those who followed up and those who did not.

Another limitation of the study was the reporting eczema in parents and siblings without a clinical verification. The question "have you, the child's father or any of your joint children ever had eczema" is a core ISAAC questions, but is most often used in combination with a question on rash located in typical places or diagnosis verified by a doctor. To the best of our knowledge, the question has not been validated in an adult population. However, the almost similar phrasing "have you ever had childhood eczema" was validated among adults in a Swedish population. The sensitivity and specificity of this question was $89.9 \%$ and $70.7 \%$, respectively [32], and an overestimation of the reported prevalence of childhood eczema among adults is therefore likely. Regarding the use of this question among children (siblings), we have validated this in a former publication [21]. This question alone, without a question identifying rash on typical location, gave a sensitivity of $96.8 \%$ and a specificity of $68.0 \%$ when validated against the UK Working Party Criteria. Adding a question of rash on typical locations decreased the sensitivity whereas the specificity increased. This gives reason to believe, that there might be an overestimation of reported eczema among the siblings, since other forms of dermatitis in young children, such as seborrhoeic dermatitis as well as nappy dermatitis might have been included. However, in case of such a misclassification, there is no reason to believe that this has changed from 6 weeks to 1 year, and could therefore not explain the differences in reporting of eczema in siblings in the two cohorts.

The strengths of this study are the large number of unselected participants as well as the prospective design. The consistency of reported eczema indicates a high reliability of the questions and the prevalence of reported eczema is well in line with the prevalence found in the PACT endpoint-study [21]. In addition, the focus is on eczema-groups only, since other studies have showed that parental eczema may be a better marker for eczema in the offspring than other parental atopic diseases $[8,33]$.

\section{Conclusions}

We found that reporting having a sibling with eczema at 1 year was significantly associated with reported eczema at 2 years. Eczema in mother as well as eczema in father was both associated with eczema 2 years. When family eczema-history was reported when index child was 1 years of age, the associations with eczema 2 years were significantly stronger for both parents if sibling(s) of the index child had eczema, and association was significantly stronger for sibling(s) reported at 1 year compared to 6 weeks. However, although siblings had eczema, the shared environment by mother and child did not result in any difference between maternal and paternal associations to eczema 2 years in index child.

The finding of different associations when familyeczema history was reported at 6 weeks compared to when family eczema-history was reported at 1 year indicate bias in information gathering and has important implications on comparability of studies measuring the effect of older sibling disease on index child's risk of eczema.

\section{Acknowledgements}

The authors would like to thank all parents, children, general practitioners and midwifes for participating in the study. A special thank to bioengineer Guri Helmersen and nurse Else Bartnes for their invaluable contribution in the PACT-study.

Funding for the PACT study was obtained from the Norwegian Department of Health and Social affairs 1997-2003, and the control cohort was funded by AstraZeneca Norway AS 2000-2001. A university scholarship from the Norwegian University of Science and Technology (NTNU) is funding MS from 2008-2012. A university scholarship from NTNU and a scholarship from Norwegian Research Council 1999-2003 funded TØ and OS. Grants were 
obtained from the Norwegian Medical Association and SINTEF Unimed 1999 A scholarship from Nidarosfondet funded TØ in 2007.

\section{Author details}

${ }^{1}$ Department of Public Health and General Practice, Norwegian University of Science and Technology, Trondheim, Norway. ${ }^{2}$ Department of Dermatology, St. Olavs Hospital, Trondheim University Hospital, Norway.

\section{Authors' contributions}

MS participated in the design of the study, performed statistical analysis and drafted the manuscript. T $\varnothing$, OS and RJ conceived the study, participated in its design and co-ordination and helped draft the manuscript.

All authors read and approved the final manuscript.

\section{Competing interests}

The authors declare that they have no competing interests.

Received: 17 December 2010 Accepted: 20 May 2011

Published: 20 May 2011

\section{References}

1. Bieber T: Atopic dermatitis. N Engl J Med 2008, 358(14):1483-1494.

2. Schultz Larsen FV, Holm NV: Atopic dermatitis in a population based twin series. Concordance rates and heritability estimation. Acta Derm Venereol Suppl (Stockh) 1985, 114:159.

3. Ruiz RG, Kemeny DM, Price JF: Higher risk of infantile atopic dermatitis from maternal atopy than from paternal atopy. Clin Exp Allergy 1992, 22(8):762-766.

4. Dold S, Wjst M, von Mutius E, Reitmeir P, Stiepel E: Genetic risk for asthma, allergic rhinitis, and atopic dermatitis. Arch Dis Child 1992, 67(8):1018-1022

5. Diepgen $T L$, Blettner M: Analysis of familial aggregation of atopic eczema and other atopic diseases by ODDS RATIO regression models. J Invest Dermatol 1996, 106(5):977-981.

6. Wang IJ, Guo YL, Hwang KC, Hsieh WS, Chuang YL, Lin SJ, Chen PC: Genetic and environmental predictors for pediatric atopic dermatitis. Acta Paediatr Taiwan 2006, 47(5):238-242.

7. Bisgaard $H$, Halkjaer LB, Hinge R, Giwercman C, Palmer C, Silveira L, Strand M: Risk analysis of early childhood eczema. J Allergy Clin Immunol 2009, 123(6):1355-1360, e1355.

8. Wadonda-Kabondo N, Sterne JA, Golding J, Kennedy CT, Archer CB, Dunnill MG: Association of parental eczema, hayfever, and asthma with atopic dermatitis in infancy: birth cohort study. Arch Dis Child 2004, 89(10):917-921.

9. Bohme M, Wickman M, Lennart Nordvall S, Svartengren M, Wahlgren CF: Family history and risk of atopic dermatitis in children up to 4 years. Clin Exp Allergy 2003, 33(9):1226-1231.

10. Zutavern A, Hirsch T, Leupold W, Weiland S, Keil U, von Mutius E: Atopic dermatitis, extrinsic atopic dermatitis and the hygiene hypothesis: results from a cross-sectional study. Clin Exp Allergy 2005, 35(10):1301-1308

11. Morar N, Willis-Owen SA, Moffatt MF, Cookson WO: The genetics of atopic dermatitis. J Allergy Clin Immunol 2006, 118(1):24-34, quiz 35-26.

12. O'Regan GM, Sandilands A, McLean WH, Irvine AD: Filaggrin in atopic dermatitis. J Allergy Clin Immunol 2009, 124(3 Suppl 2):R2-6.

13. Strachan DP: Hay fever, hygiene, and household size. BMJ 1989, 299(6710):1259-1260.

14. Karmaus W, Botezan C: Does a higher number of siblings protect against the development of allergy and asthma? A review. J Epidemiol Community Health 2002, 56(3):209-217.

15. Kjellman Nl: Atopic disease in seven-year-old children. Incidence in relation to family history. Acta Paediatr Scand 1977, 66(4):465-471.

16. Kulig M, Bergmann R, Edenharter $G$, Wahn U: Does allergy in parents depend on allergy in their children? Recall bias in parental questioning of atopic diseases. Multicenter Allergy Study Group. J Allergy Clin Immunol 2000, 105(2 Pt 1):274-278.

17. Moberg C, Meding B, Stenberg B, Svensson A, Lindberg M: Remembering childhood atopic dermatitis as an adult: factors that influence recollection. $\mathrm{Br} J$ Dermatol 2006, 155(3):557-560.
18. Naleway AL, Belongia EA, Greenlee RT, Kieke BA Jr, Chen RT, Shay DK: Eczematous skin disease and recall of past diagnoses: implications for smallpox vaccination. Ann Intern Med 2003, 139(1):1-7.

19. Storro O, Oien T, Dotterud CK, Jenssen JA, Johnsen R: A primary healthcare intervention on pre- and postnatal risk factor behavior to prevent childhood allergy. The Prevention of Allergy among Children in Trondheim (PACT) study. BMC Public Health 2010, 10(443)

20. Oien T, Storro O, Johnsen R: Assessing atopic disease in children two to six years old: reliability of a revised questionnaire. Prim Care Respir J 2008, 17(3):164-168.

21. Smidesang I, Saunes $M$, Storro O, Oien T, Holmen $T L$, Johnsen $R$, Henriksen $\mathrm{AH}$ : Atopic dermatitis among 2-year olds; high prevalence, but predominantly mild disease-the PACT study, Norway. Pediatr Dermatol 2008, 25(1):13-18.

22. Johnke H, Vach W, Norberg LA, Bindslev-Jensen C, Host A, Andersen KE: A comparison between criteria for diagnosing atopic eczema in infants. $\mathrm{Br}$ J Dermatol 2005, 153(2):352-358.

23. Williams HC: Epidemiology of atopic dermatitis. Clin Exp Dermatol 2000, 25(7):522-529.

24. Godfrey K: Fetal and perinatal origins of atopic dermatitis. In Atopic dermatitis. Edited by: Williams HC. Cambridge: Cambridge University Press; 2000:125-138.

25. Wen HJ, Chen PC, Chiang TL, Lin SJ, Chuang YL, Guo YL: Predicting risk for early infantile atopic dermatitis by hereditary and environmental factors. Br J Dermatol 2009, 161(5):1166-1172.

26. Litonjua AA, Carey VJ, Burge HA, Weiss ST, Gold DR: Parental history and the risk for childhood asthma. Does mother confer more risk than father? Am J Respir Crit Care Med 1998, 158(1):176-181.

27. Brown SJ, Relton CL, Liao H, Zhao Y, Sandilands A, McLean WH, Cordell HJ, Reynolds NJ: Filaggrin haploinsufficiency is highly penetrant and is associated with increased severity of eczema: further delineation of the skin phenotype in a prospective epidemiological study of 792 school children. Br J Dermatol 2009, 161(4):884-889.

28. Palmer CN, Irvine AD, Terron-Kwiatkowski A, Zhao Y, Liao H, Lee SP, Goudie DR, Sandilands A, Campbell LE, Smith FJ, O'Regan GM, Watson RM, Cecil JE, Bale SJ, Compton JG, DiGiovanna JJ, Fleckman P, Lewis-Jones S, Arseculeratne G, Sergeant A, Munro CS, El Houate B, McElreavey K, Halkjaer LB, Bisgaard H, Mukhopadhyay S, McLean WH: Common loss-offunction variants of the epidermal barrier protein filaggrin are a major predisposing factor for atopic dermatitis. Nat Genet 2006, 38(4):441-446.

29. Ekelund E, Lieden A, Link J, Lee SP, D'Amato M, Palmer CN, Kockum I, Bradley M: Loss-of-function variants of the filaggrin gene are associated with atopic eczema and associated phenotypes in Swedish families. Acta Derm Venereol 2008, 88(1):15-19.

30. Bisgaard H, Simpson A, Palmer CN, Bonnelykke K, McLean I, Mukhopadhyay S, Pipper CB, Halkjaer LB, Lipworth B, Hankinson J, Woodcock A, Custovic A: Gene-environment interaction in the onset of eczema in infancy: filaggrin loss-of-function mutations enhanced by neonatal cat exposure. PLoS Med 2008, 5(6):e131.

31. Illi S, von Mutius E, Lau S, Nickel R, Gruber C, Niggemann B, Wahn U: The natural course of atopic dermatitis from birth to age 7 years and the association with asthma. J Allergy Clin Immunol 2004, 113(5):925-931.

32. Stenberg B, Lindberg M, Meding B, Svensson A: Is the question 'Have you had childhood eczema?' useful for assessing childhood atopic eczema in adult population surveys? Contact Dermatitis 2006, 54(6):334-337.

33. Alm B, Aberg N, Erdes L, Mollborg P, Pettersson R, Norvenius SG, Goksor E, Wennergren G: Early introduction of fish decreases the risk of eczema in infants. Arch Dis Child 2009, 94(1):11-15.

\section{Pre-publication history}

The pre-publication history for this paper can be accessed here: http://www.biomedcentral.com/1471-5945/11/11/prepub

\section{doi:10.1186/1471-5945-11-11}

Cite this article as: Saunes et al:: Family eczema-history in 2-year olds with eczema; a prospective, population-based study. The PACT-study, Norway. BMC Dermatology 2011 11:11. 